\title{
KESESUAIAN DESAIN OPERASIONAL KAPAL INKAMINA 163 BERBASIS DI PPP SADENG YOGYAKARTA
}

\author{
OPERATIONAL DESIGN SUITABILITY OF AN INKAMINA 163 FISHING VESEL BASED \\ IN SADENG FISHING PORT, YOGYAKARTA
}

\author{
Paduartama Tandipuang, Yopi Novita dan Budhi H. Iskandar \\ Departemen Pemanfaatan Sumberdaya Perikanan, Fakultas Perikanan dan Ilmu Kelautan, Institut Pertanian Bogor, \\ Kampus IPB Dramaga Bogor, 16680, Indonesia \\ E-mail: tandipuangputra@ymail.com
}

Diterima tanggal: 13 Nopember 2014, diterima setelah perbaikan: 26 Juli 2015, disetujui tanggal: 30 Juli 2015

\begin{abstract}
ABSTRAK
Nelayan di Pelabuhan Perikanan Pantai Sadeng, Provinsi Daerah Istimewa Yogyakarta ragu untuk mengoperasikan kapal ikan bantuan sampai batas maksimum ZEEI. Keraguan nelayan terletak pada kemampuan operasional kapal. Penelitian ini bertujuan untuk menganalisis kesesuaian kapasitas muat yang tersedia di atas kapal dengan rencana target operasional kapal, dan menganalisis area kerja di lantai dek kapal. Metode yang digunakan adalah metode studi kasus. Kapal Inkamina 163 menjadi objek penelitian. Data dianalisis dengan cara comparative-numeric untuk mengkaji kesesuaian desain kapal dan untuk mengetahui area kerja pada dek kapal. Analisis kesesuaian desain juga dilakukan dengan mengacu pada KEPMENKP No. 21/2004. Hasil kajian menunjukkan bahwa Kapal Inkamina 163 memiliki kapasitas muat yang sebagian besar sudah dapat memenuhi rencana target operasional kapal. Tata letak muatan di lantai dek kapal Inkamina 163 telah sesuai dengan kebutuhan area kerja ABK. Kapal tersebut telah memenuhi 7 dari 8 syarat yang dijadikan acuan dalam KEPMENKP No. 21/2004.
\end{abstract}

Kata kunci: Inkamina, kapal ikan, kapasitas muat, comparative numeric.

\section{ABSTRACT}

Fishermen in Sadeng Fishing Port, of DI Yogyakarta Province, are still in doubt to operate Inkamina vessels until ZEEI in the Indian Ocean. Fishermen are doubt about the operational ability of fishing vessels. This research aimed to analyze the suitability of loading capacity available on board of the ship, with operational plan target, and analyze suitability of the layout on the vessel deck. Case study method is used in this research in which Inkamina 163 fishing vessels become the object of research. Data were analyzed by means of comparative-numeric to assess the suitability of the design of the ship and to know the working area on deck. In addition, analysis of the suitability of the design is also refers to KEPMENKP No. 21/2004. The results showed that Inkamina 163 fishing vessel has a load capacity largely been able to fulfill the plan of the ship operational target. Working area on the main deck crew is already met. This ship has satisfied 7 from 8 requirements in KEPMENKP No. 21/2004.

Keywords: Inkamina, fishing vessel, load capacity, comparative numeric.

\section{PENDAHULUAN}

Provinsi Daerah Istimewa Yogyakarta (DIY) merupakan salah satu provinsi penerima kapal penangkap ikan bantuan dari pemerintah. Kapal bantuan ini dinamakan kapal Inkamina. Kapal Inkamina yang ada di Provinsi DIY ditambatlabuhkan di Pelabuhan Perikanan Pantai (PPP) Sadeng, Kabupaten Gunung Kidul. Kapal- kapal Inkamina yang ada di pelabuhan tersebut jarang digunakan oleh nelayan untuk melakukan operasi penangkapan ikan. Nelayan di PPP Sadeng meragukan kemampuan operasional kapal tersebut. Operasi penangkapan ikan terjauh dilakukan di 60 mil. Mereka belum dapat mengoperasikan kapal tersebut hingga 200 mil di ZEEI. Potensi perikanan laut pada perairan ZEEI di Provinsi DIY belum dapat dimanfaatkan dengan optimal. 
Salah satu faktor yang menentukan dalam desain suatu kapal penangkap ikan adalah kesesuaian kapasitas muat kapal dengan rencana target operasi penangkapan dan keselamatan kerja di atas kapal. Setiap kapal penangkap ikan harus dapat memenuhi faktor tersebut untuk menunjang keberhasilan dan keamanan suatu operasi penangkapan.

Beberapa penelitian mengenai desain kapal dan keselamatan kerja di laut telah dilakukan. Usaha perbaikan kualitas kapal ikan PSP 01 oleh Susanto (2010), dilakukan dengan cara simulasi terhadap modifikasi dimensi utama kapal agar diperoleh acuan untuk redesign. Marjoni (2009) melakukan penelitian menggunakan kapal purse seine yang mendominasi di Pelabuhan perikanan Pantai Lampulo. Kapal-kapal tersebut hanya dioperasikan pada 12 mil sehingga potensi perikanan laut di perairan Provinsi Nangro Aceh Darussalam pada jarak lebih dari 12 mil belum dapat dikelola secara maksimal.

Ketersediaan luas area kerja di dek kapal harus mencukupi kebutuhan ABK karena dapat mempengaruhi keamanan kerja. Piniella et al. (2008) mengemukanan dalam penelitiannya bahwa telah banyak penelitian yang menganalisis mengenai rendahnya tingkat keamanan kerja pada perikanan tangkap seperti: Chau-vin and Lebouar (2007) melakukan penelitian mengenai kecelakaan kerja di industri perikanan laut Perancis; Murray and Tilley (2006) melakukan penelitian pada kolompok nelayan di Newfoundland, Canada; Brooks (2005) di Australia; dan Jin \& Thunberg (2005) di daerah penangkapan ikan Timur Laut Amerika Serikat.

Berdasarkan pemaparan di atas, perlu dilakukan suatu kajian untuk menganalisis kesesuaian desain kapal Inkamina ditinjau dari kapasitas muat dan tata letak di dek kapal yang terkait dengan ketersediaan area kerja. Tujuan penelitian ini adalah: 1) menganalisis kesesuaian kapasitas muat yang tersedia di atas kapal dengan rencana target operasional kapal, dan 2) menganalisis area kerja di lantai dek kapal.

Pencapaian untuk tujuan pertama penelitian ini dilakukan analisis perbandingan dimensi utama kapal dan coefficient of fineness terhadap kapal tipe encircling gear di Indonesia, operational general arrangement, dan kapasitas muat kapal. Tujuan kedua pada penelitian ini menghubungkan antara ketersediaan area kerja dengan kebutuhan ABK di dek utama kapal Inkamina 163.

Hasil kajian dalam penelitian ini dapat digunakan sebagai bahan acuan untuk redesign agar kapal Inkamina 163 dan juga kapal penangkap ikan yang lain dapat memenuhi target operasi.

\section{BAHAN DAN METODE}

\section{Lokasi dan Waktu Penelitian}

Penelitian dilakukan pada bulan April sampai dengan bulan Mei 2014 di Pelabuhan Perikanan Pantai (PPP) Sadeng, Kelurahan Pucung, Kecamatan Girisubo, Kabupaten Gunung Kidul, Provinsi Daerah Istimewa Yogyakarta.

\begin{abstract}
Alat dan Metode
Alat yang digunakan untuk penelitian ini yaitu: roll meter $(20 \mathrm{~m})$, tali kenur,tali rafia, pemberat (bandul), waterpass, senter, penggaris 20 dan 60 $\mathrm{cm}$, senter, digital camera, alat tulis, kertas millimeter block (1x1 m), dan laptop. Penelitian ini menggunakan metode studi kasus. Fokus kajian dilakukan terhadap kapal Inkamina 163 yang berbasis di PPP Sadeng, DIY. Jenis dan metode pengambilan data disajikan pada Tabel 1 .
\end{abstract}

\begin{abstract}
Analisis Data
Data dianalisis dengan cara comparative-numeric. Analisis comparative-numeric yang pertama dilakukan dengan membandingkan antara volume ruang yang telah terpasang di kapal dengan volume ruang tersebut berdasarkan estimasi secara teoritis. Analisis comparative-numeric yang kedua dilakukan dengan membandingkan luas area terpakai dengan luas area tersedia di atas lantai dek kapal. Selain itu, analisis juga dilakukan dengan mengacu pada KEPMENKP No. 21 (2004).
\end{abstract}

\section{HASIL DAN PEMBAHASAN}

\section{Desain Kapal \\ Kapal ikan bantuan yang dijadikan objek penelitian adalah Kapal Inkamina 163 berukuran 32 GT yang berbasis di PPP Sadeng, Provinsi DIY. Dimensi utama kapal tersebut adalah sebagai berikut: Lpp}


(13,65 m), B (4,74 m), D (2,04 m), dan d (1,632 $\mathrm{m})$.

Perbandingan ukuran dimensi utama kapal Inkamina 163 disajikan pada Tabel 2. Kisaran nilai perbandingan dimensi utama kapal ikan di Indonesia yang telah dilakukan oleh Iskandar dan Pujiati (1995) dijadikan pembanding rasio dimensi utama kapal Inkamina 163.

Tabel 1. Metode pengambilan data dari tiap jenis data

Table 1. The data collection method for each type of data

\begin{tabular}{lc}
\hline \multicolumn{1}{c}{ Jenis data } & Metode pengambilan data \\
\hline $\begin{array}{l}\text { Tujuan 1 : Menganalisis kesesuaian kapasitas muat yang tersedia di atas kapal dengan rencana target } \\
\text { operasional kapal }\end{array}$ & Pengukuran langsung \\
\hline Palka & Pengukuran langsung \\
Tangki BBM & Pengukuran langsung \\
Tangki air tawar & Pengukuran langsung \\
Ruang ABK & Data hasil tangkapan di KUB \\
Rata-rata jumlah hasil tangkapan maksimum & Data pemakaian BBM di KUB \\
per trip & Perhitungan dan pengukuran langsung \\
Rata-rata pemakaian BBM per trip & \\
Jumlah ABK dan rata-rata ukuran tubuhnya & Pengukuran langsung \\
\hline Tujuan 2 : Kesesuaian tata letak muatan di dek kapal & Pengukuran langsung \\
\hline Luas area di lantai dek & Pengecekan langsung \\
Luas area yang terpakai & \\
Kondisi bagian kapal &
\end{tabular}

Tabel 2. Perbandingan ukuran dimensi utama kapal

Table 2. Size comparison of vessel main dimension

\begin{tabular}{cccccc}
\hline \multirow{2}{*}{$\begin{array}{c}\text { Rasio dimensi } \\
\text { utama }\end{array}$} & \begin{tabular}{c} 
Kapal \\
Inkamina \\
\cline { 3 - 5 }
\end{tabular} & \multicolumn{4}{c}{ Kelompok kisaran ukuran kapal ikan di Indonesia ${ }^{*}$ ) } \\
\cline { 3 - 6 } & 163 & Static gear & $\begin{array}{c}\text { Encircling } \\
\text { gear }\end{array}$ & Towed gear & $\begin{array}{c}\text { Multi- } \\
\text { purpose }\end{array}$ \\
\hline L/B & 2.88 & $2,83-11,12$ & $2.06-9.30$ & $2,86-8,30$ & $2,88-9,42$ \\
L/D & 6.96 & $4.58-17.28$ & $4.55-17.43$ & $7,20-15,12$ & $8,69-17,55$ \\
B/D & 2.32 & $0.96-4.68$ & $0.5-5.00$ & $1,25-4,41$ & $0,35-6,09$ \\
\hline
\end{tabular}

Sumber: Hasil pengukuran

Keterangan : ${ }^{*}$ Iskandar dan Pujiati, 1995.

\section{Rasio dimensi utama}

Menurut Iskandar (2007) mendesain kapal ikan yang terbuat dari bahan kayu, perhatian utama ditujukan pada dimensi kapal panjang antara garis tegak (L), lebar kapal (B), dan dalam kapal (D). Perbandingan dimensi tersebut merupakan parameter awal menggambarkan bentuk dan jenis kapal.

Berdasarkan data pada Tabel 2, dimensi utama kapal Inkamina 163 masuk dalam dua kelompok kisaran ukuran jenis kapal ikan di Indonesia yakni kelompok static gear dan encircling gear. Hasil perbandingan tersebut menyatakan bahwa dimensi kapal ikan ini pada umumnya digunakan oleh nelayan di Indonesia untuk mengoperasikan alat tangkap baik jenis encircling gear maupun jenis static gear.

\section{Coefficient of Finenness}

Iskandar dan Pujiati (1995) telah melakukan pengelompokan kisaran nilai koefisien bentuk (coefficient of fineness) kapal ikan yang ada di Indonesia. Tabel 3 menunjukkan perbandingan 
nilai coefficient of fineness kapal Inkamina 163 dengan kisaran nilai coefficient of fineness kapalkapal ikan di Indonesia.

Menurut Gillmer dan Johnson (1911), bentuk proporsi bagian kapal yang terendam air dapat dilihat dengan jelas untuk menentukan gemuk atau langsing, atau sedang, dari hasil perbandingan dimensi atau nilai koefisien bentuk (coefficient of fineness). Dari hasil perbandingan nilai koefisien, kapal Inkamina 163 memiliki badan kapal yang cenderung gemuk. Kapal tersebut cenderung lebih ramping untuk tipe kapal encircling gear, namun cenderung gemuk untuk tipe kapal static gear di Indonesia.

\section{Operational General Arrangement}

Pengaturan tata ruang dan muatan kapal Inkamina 163 saat kondisi siap beroperasi, dapat dilihat melalui operational general arrangement yang disajikan pada Gambar 1.

Tabel 3. Perbandingan kisaran nilai coefficient of fineness Kapal Inkamina 163 dengan kapal ikan di Indonesia

Table 3. Comparison of the coefficient of fineness value range Inkamina 163 with fishing vessel in Indonesia

\begin{tabular}{|c|c|c|c|}
\hline \multirow[t]{2}{*}{ Coefficient } & \multirow{2}{*}{$\begin{array}{c}\text { Kapal } \\
\text { Inkamina } \\
163\end{array}$} & \multicolumn{2}{|c|}{$\begin{array}{c}\text { Kisaran nilai coefficient } \\
\text { of fineness kapal ikan di } \\
\text { Indonesia }\end{array}$} \\
\hline & & $\begin{array}{c}\text { Encircling } \\
\text { gear }\end{array}$ & Static gear \\
\hline $\mathrm{Cb}$ & 0,57 & $0,56-0,67$ & $0,39-0,70$ \\
\hline $\mathrm{Cp}$ & 0,75 & $0,60-0,79$ & $0,56-0,80$ \\
\hline $\mathrm{Cw}$ & 0,86 & $0,78-0,88$ & $0,65-0,85$ \\
\hline $\mathrm{C}_{\otimes}$ & 0,78 & $0,84-0,96$ & $0,63-0,91$ \\
\hline Cvp & 0,66 & $0,68-0,86$ & $0,60-0,82$ \\
\hline
\end{tabular}

Sumber: Hasil pengukuran

Keterangan : *) Iskandar dan Pujiati, 1995.

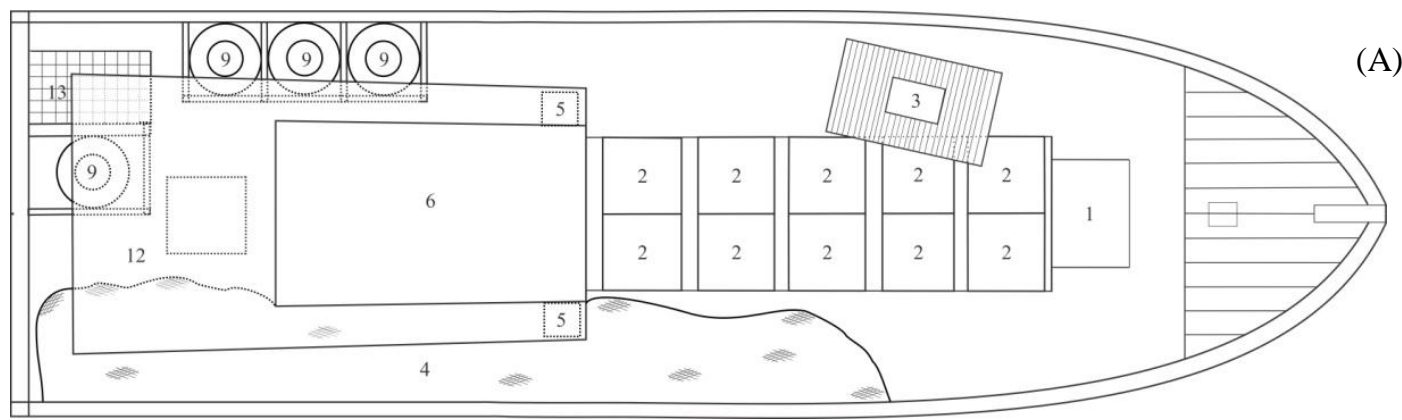

(B)

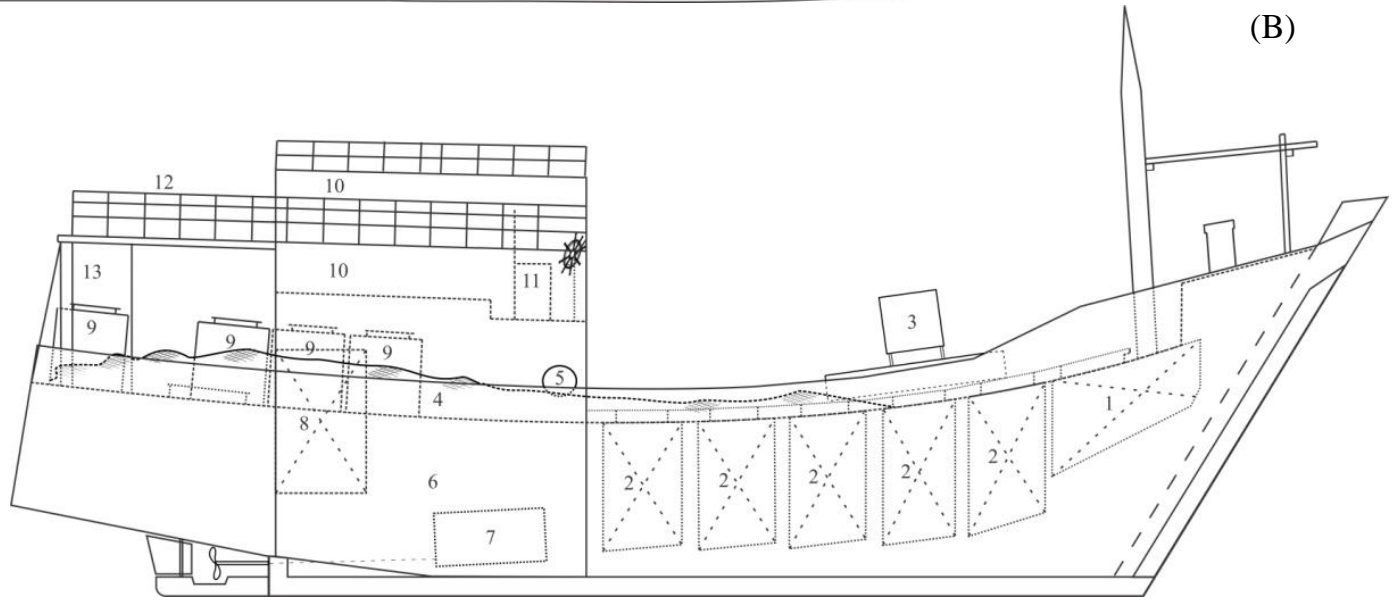

Keterangan :
1. Gudang
5.. Roller
6. Ruang mesin
9. Tangki air tawar
2. Palka ikan
7. Mesin
10. Ruang perbekalan
3. Pelampung lampu
8. Tangki BBM
11. Kursi nahkoda
12. Tempat ABK

13. Tempat memasak

Gambar 1. Operational general arrangement Kapal Inkamina 163, (A) tampak atas, dan (B) tampak samping Figure 1. General arrangement of Inkamina 163 fishing vessel, (A) above view, and (B) side view Sumber: Koleksi pribadi 


\section{Kapasitas Muat Kapal}

Kapasitas muat kapal (load capacity) merupakan daya tampung kapal untuk berbagai jenis muatan pada setiap ruang yang ada. Perbandingan antara volume terpasang dan volume estimasi dilakukan untuk mengetahui keefektifan dan keefisienan dimensi ruang. Volume terpasang adalah volume ruang eksisting di kapal, dan volume estimasi adalah volume ruang yang diestimasi berdasarkan faktor-faktor desain yang ada. Nilai volume terpasang dan estimasi disajikan pada Tabel 4.

Tabel 4. Perbandingan volume terpasang pada Kapal Inkamina 163 dengan volume estimasi

Table 4. Comparison of the mounted volume with a estimated volume on Inkamina 163

\begin{tabular}{lccc}
\hline Ruang & $\begin{array}{c}\text { Volume } \\
\text { terpasang } \\
\left(\mathrm{m}^{3}\right)\end{array}$ & $\begin{array}{c}\text { Volume } \\
\text { estimasi } \\
\left(\mathrm{m}^{3}\right)\end{array}$ & $\begin{array}{c}\text { Persentase } \\
\text { perbandingan }\end{array}$ \\
\hline $\begin{array}{l}\text { Palka } \\
\text { ikan } \\
\text { Ruang } \\
\text { mesin }\end{array}$ & 23,5 & 17,75 & $>32,39 \%$ \\
$\begin{array}{l}\text { Tangki } \\
\text { BBM } \\
\text { Tangki } \\
\text { air } \\
\text { tawar }\end{array}$ & 3,11 & 2,79 & $>11,46 \%$ \\
Ruang & 2,27 & 0,825 & $>175,15 \%$ \\
ABK & $9,06 \mathrm{~m}^{2}$ & $14,04 \mathrm{~m}^{2}$ & $<64,5 \%$ \\
\hline
\end{tabular}

Sumber: Hasil analisis

Keterangan:

$<=$ Volume terpasang lebih besar dari volume estimasi,

$>=$ Volume terpasang lebih kecil dari volume estimasi.

Palka ikan merupakan ruangan di bawah dek yang digunakan untuk tempat menyimpan hasil tangkapan (Wahyono, 2011). Volume estimasi palka ikan diperoleh dari hasil perhitungan volume rata-rata jumlah ikan hasil penangkapan maksimum selama kapal Inkamina 163 beroperasi. Hasil perbandingan volume palka ikan menunjukkan bahwa volume palka yang terpasang lebih besar dari volume palka estimasi. Kondisi ini dapat ditolerir karena mempertimbangkan hasil tangkapan maksimum yang pernah diperoleh hingga palka penuh.

Perkiraan volume ruang mesin kapal yang ideal adalah jika memenuhi faktor keamanan dan kenyamanan kerja ABK. Hal ini dipengaruhi oleh ketersediaan area kerja ABK, dimensi mesin, pelepasan panas dan gas buang, serta sirkulasi udara. Area kerja ABK dan dimensi mesin menjadi faktor perhitungan untuk volume estimasi ruang mesin Kapal Inkamina 163. Volume terpasang ruang mesin kapal tersebut lebih besar dari volume estimasi.

Volume estimasi tangki BBM kapal Inkamina 163 diperoleh dari hasil perhitungan laju konsumsi BBM beserta bahan bakar cadangan jika dioperasikan di perairan ZEEI yakni pada jarak 200 mil. Tangki BBM Kapal Inkamina 163 memiliki volume terpasang lebih besar dari volume estimasi. Volume terpasang tangki BBM yang berlebih $(11,46 \%)$ dapat memuat 350 liter solar $(310,07 \mathrm{~kg})$ dapat digunakan untuk menempuh jarak \pm 25 mil dengan kecepatan ratarata 7 knot. Akimov (1970) menyatakan bahwa dalam tangki BBM harus tersedia minimal 3-5 \% ruang kosong dari volume total tangki. Hal ini bertujuan untuk memberikan ruang pemuaian BBM.

Terdapat 4 buah drum tangki air tawar di kapal Inkamina 163. Tiap drum berkapasitas $0,520 \mathrm{~m}^{3}$ (520 liter) air tawar. Volume estimasi tangki air tawar diperoleh dari hasil perhitungan jumlah air tawar yang dikonsumsi oleh seluruh ABK (13 orang) selama satu trip. Hasil perbandingan menyatakan bahwa volume terpasang lebih besar dari volume estimasi. Daya tampung air tawar pada volume terpasang yang lebih besar ini setara dengan 3,978 ton air tawar. Berat air tawar ini digunakan sebagai water ballast pada kapal.

Kapal ikan yang memiliki palka ikan hidup akan dipengaruhi oleh efek free surface saat rolling., Keberadaan free surface akan meningkatkan damping moment coefficient kapal (Lee et al., 2005). Menurut Novita (2011), permukaan muatan cair (liquid) yang masih dapat bergerak bebas dapat mempengruhi kualitas stabilitas kapal.

Tangki penampungan air tawar yang ditempatkan di atas dek kapal Inkamia 163 dapat memberikan efek free surface pada kapal. Tangki-tangki air tawar yang ada pada kapal Inkamina 163 memiliki diameter yang kecil sehingga efek free surface yang akan ditimbulkan tidak terlalu mempengaruhi stabilitas kapal tersebut.

Letak titik berat mempengaruhi stabilitas kapal. Penelitian yang dilakukan Manulang (2008) 
menyatakan bahwa jika berat muatan yang berada di bawah dek kapal berkurang dan terjadi penambahan muatan di atas dek maka titik berat akan bergerak ke atas. Letak titik berat (KG) mempengaruhi besar kecilnya lengan penegak GZ yang terbentuk pada saat mengalami keolengan. Peletakan muatan di atas dek berupa tangki air tawar pada kapal Inkamina 163 akan lebih cenderung mengganggu stabilitas kapal karena titik berat kapal akan berpindah ke atas atau nilai $\mathrm{KG}$ menjadi semakin besar.

Kapal Inkamina 163 tidak memiliki desain ruang khusus untuk ABK. Tempat ABK beristirahat yang ada merupakan modifikasi ABK. Luas estimasi untuk tempat $\mathrm{ABK}$ diperoleh dari hasil perhitungan rata-rata ukuran tubuh nelayan. Luas tempat $\mathrm{ABK}$ yang terpasang ini $64,5 \%$ lebih kecil dari luas estimasi dan hanya dapat menampung 5 orang dari 13 orang $\mathrm{ABK}$.

Kondisi tempat ABK pada kapal Inkamina 163 yang kurang memadai tersebut dapat berdampak pada kondisi fisik para ABK. Kapal yang bergerak pada enam sumbu (buritan kedepan, lateral, vertikal, roll, pitch dan yaw), dapat mengganggu kegiatan dan kesehatan ABK. Lebih dari $79 \%$ ABK yang mengalami kelelahan dan permasalahan tidur (Haward et al., 2009). Aktifitas kerja yang intens dan berkepanjangan yakni dalam hal penangkapan ikan dapat menyebabkan kelelahan. Kelelahan ini merupakan faktor umum penyebab kecelakaan kerja pada pekerjaan penangkapan ikan (ILO, 1999).

\section{Area Kerja di Dek Kapal Inkamina 163}

Dek merupakan lingkungan kerja nelayan yang berbahaya karena merupakan pijakan yang terusmenerus mengalami pergerakan dan tidak stabil (Husberg et al., 2001). Berdasarkan distribusi jenis kegiatan di dek, Fyson (1985) melakukan perencanaan pembagian area pada dek kapal menjadi 5 bagian area kerja: dek buritan, dek samping, rumah kemudi, dek kerja utama (main working deck), dan dek haluan. Analisis area kerja dilakukan di dek utama (main deck) dan di dek kerja utama (main working deck).

Bangunan dan muatan yang berada di main deck kapal Inkamina 163 mulai dari arah haluan ke buritan, dipaparkan pada Tabel 5. Gambaran letak bangunan timbul dan muatan kapal ini dapat dilihat kembali pada operational general arrangement di Gambar 1.

Tabel 5. Bangunan timbul dan muatan di dek kapal Inkamina 163

Table 5. Arise Building and cargo on the deck of Inkamina 163

\begin{tabular}{|c|c|c|}
\hline $\begin{array}{c}\text { Bangunan } \\
\text { timbul }\end{array}$ & Muatan & $\begin{array}{c}\text { Keterangan letak di } \\
\text { dek }\end{array}$ \\
\hline $\begin{array}{l}\text { Tutup palka } \\
\text { gudang }\end{array}$ & & $\begin{array}{l}\text { di bagian depan dek } \\
\text { utama dan di } \\
\text { belakang ruang } \\
\text { kemudi }\end{array}$ \\
\hline $\begin{array}{c}\text { Tutup palka } \\
\text { ikan }\end{array}$ & & $\begin{array}{l}\text { di sepanjang dek } \\
\text { utama }\end{array}$ \\
\hline $\begin{array}{l}\text { Ruang } \\
\text { kemudi }\end{array}$ & & di midship \\
\hline $\begin{array}{l}\text { Tangki air } \\
\text { tawar }\end{array}$ & & $\begin{array}{l}\text { sisi kiri di belakang } \\
\text { setelah midship dan } \\
\text { bagian tengah } \\
\text { buritan kapal }\end{array}$ \\
\hline \multirow[t]{3}{*}{ Dapur } & & di sisi kiri buritan \\
\hline & $\begin{array}{l}\text { Pelampung } \\
\text { lampu }\end{array}$ & $\begin{array}{l}\text { sisi kiri di bagian } \\
\text { depan dek utama }\end{array}$ \\
\hline & Jaring & $\begin{array}{l}\text { memanjang dari } \\
\text { depan rumah dek } \\
\text { hingga } 3 / 4 \text { bagian } \\
\text { dek utama }\end{array}$ \\
\hline
\end{tabular}

Sumber: Hasil identifikasi

Area tutupan merupakan daerah terpakai pada dek yang ditempati oleh muatan atau bangunan. Area bebas pada kapal adalah daerah sisa yang tidak ditempati oleh bangunan maupun muatan apapun. Perbandingan luas area tutupan dan area bebas di main deck kapal Inkamina 163, disajikan pada Gambar 3.

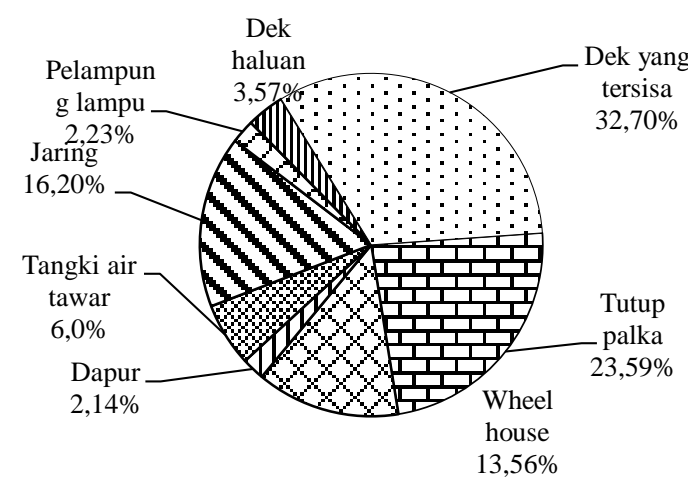

Gambar 2. Perbandingan luas area tutupan dan area bebas pada dek keseluruhan

Figure 2. Comparison of cover area and free area on main deck

Sumber: Hasil analisis 
Pengkajian juga dilakukan pada dek kerja utama (main working deck). Main working deck pada umumnya merupakan bagian dek dengan area paling luas di dek utama (main deck) kapal ikan. Analisis area kerja pada main working deck dilakukan karena dek ini merupakan tempat ABK melakukan pekerjaan meliputi pengoperasian alat tangkap, penanganan alat tangkap dan penyortiran ikan. Seluruh ABK yang bekerja di main working deck memiliki tingkat resiko bahaya yang tinggi. Hal tersebut diungkapkan oleh Antao dkk (2008) yang menyatakan bahwa mayoritas pekerjaan yang dilakukan oleh $\mathrm{ABK}$ berada di main working deck kapal penangkap ikan. Dek yang selalu bergerak menyebabkan kondisi ABK yang selalu berada dalam keadaan yang tidak seimbang saat bekerja. Sebagian besar waktu kerja berada dalam keadaan basah dan berada pada area yang berbahaya karena terdapat berbagai peralatan untuk operasi penangkapan ikan.

Juragan panggung merupakan pekerjaan paling berbahaya kemudian disusul oleh penarik jaring dan juru mudi (Suryanto, 2012). Menurut Suryanto et al. (2013), kondisi pekerja yang paling berbahaya adalah ABK yang menarik jaring di kapal pukat cincin di Selat Bali.

Perbandingan luas area tutupan dan area bebas di main working deck disajikan pada Gambar 4.

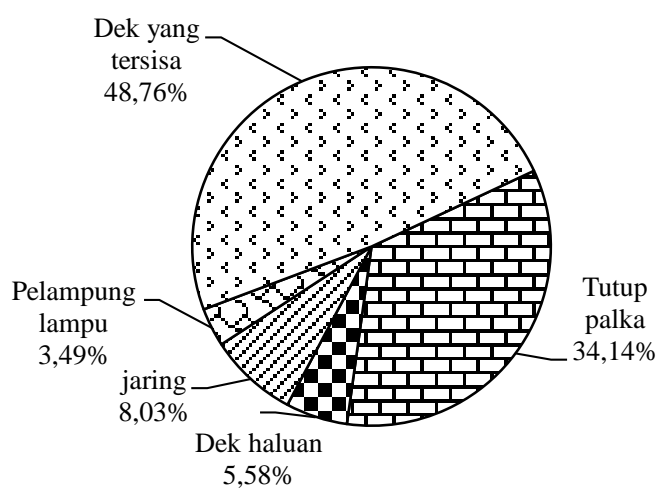

Gambar 3. Perbandingan luas area tutupan dan area bebas pada dek utama

Figure 3. Comparison of cover area and free area on main deck

Sumber: Hasil analisis

Luas total dek Kapal Inkamina 163 mulai dari haluan hingga buritan adalah sebesar $62,98 \mathrm{~m}^{2}$. Luas area bebas adalah sebesar 32,70\% $\left(20,59 \mathrm{~m}^{2}\right)$ dari luas main deck. Hal ini menggambarkan bahwa dari luas main deck yang tersedia, terdapat $32,70 \%$ bagian yang dapat dijadikan tempat ABK berpijak dan melakukan kegiatan.

Luas area bebas yang tersisa di main working deck adalah sebesar $48,76 \%\left(17,94 \mathrm{~m}^{2}\right)$. Area sisa tersebut masih mencukupi kebutuhan kerja 12 ABK. Area kerja untuk ABK pada main working deck telah tercukupi, namun masih diperlukan kewaspadaan serta kehati-hatian para ABK saat melakukan pekerjaan. Kondisi letak muatan di area kerja pada main working deck kapal Inkamina 163 yang tidak teratur dapat mengganggu aktifitas bahkan dapat mengancam keselamatan ABK.

Kecelakaan kerja pada kapal penangkap ikan jenis seine netting, sering kali disebabkan oleh peletakan muatan yang tidak tepat pada dek kapal (Piniella et al., 2008). Dalam penelitian tersebut diungkapkan bahwa kecelakaan yang terjadi pada jenis kapal tersebut disebabkan oleh luka bakar atau kebakaran akibat minyak atau gas dari lampu.

Lincoln et al. (2006) menyatakan bahwa $23 \%$ nelayan cedera disebabkan karena terjerat atau terbentur pada perlengkapan seperti tali alat tangkap, katrol, winch, atau peralatan yang berada di atas geladak. Dari hasil penelitian yang telah dilakukan oleh Dickey dan Ellis (2006) tercatat selama tahun 1994-2004, 641 nelayan meninggal di Amerika Serikat. Nelayan yang meninggal tersebut, 332 nelayan (52 \%) meninggal karena kapal tenggelam dan 184 (29 \%) kematian akibat terjatuh ke laut, serta selebihnya disebabkan karena berbagai penyebab termasuk $51,8 \%$ cidera saat bekerja di geladak. Wang et al. (2005) menyatakan bahwa penyebab terbesar kecelakaan kapal ikan adalah kelalaian $\mathrm{ABK}$, pengangkatan peralatan, dan peralatan untuk menagkap ikan. Seluruh bangunan timbul dan peralatan yang ada pada main deck dapat menjadi ancaman terjadinya kecelakaan kerja. Kemungkinan kecelakaan yang disebabkan oleh human error dapat diminimalisisr dengan cara melakukan penataan seluruh perlatan dengan benar dan rapi.

Menurut Tsai dan Su (2004) dari banyaknya tingkat kecelakaan kapal penangkap ikan yang terjadi, tidak ada hubungan yang positif antara tingkat kecelakaan dengan akibat yang ditimbulkan oleh kecelakaan tersebut. 
Tabel 6. Syarat desain dan peralatan kapal penangkap ikan

1 Persyaratan minimal untuk kapal penangkap ikan :

a. Mempunyai dek atau dek untuk penerimaan dan penanganan yang dirancang dan di tata sedemikian rupa sehingga cukup luas untuk melakukan penanganan, penampungan, dan pemisahan setiap hasil tangkapan; mudah dibersihkan serta melindungi produk dari sinar matahari dan sumber kotoran atau kon taminasi;

b. Sistem pemindahan hasil tangkapan dari tempat penerimaan ke tempat penanganan harus memenuhi persyaratan higienis;

c. Tempat penanganan untuk preparasi hasil tangkapan harus cukup luas dan memenuhi persyaratan higienis. Ruang tersebut harus dirancang dan ditata sedemikian rupa untuk mencegah kontaminasi terhadap produk;

d. Tempat penyimpanan produk akhir harus cukup luas dan dirancang sedemikian rupa agar mudah dibersihkan;

e. Apabila dilakukan penanganan limbah, maka limbah tersebut harus ditampung di tempat pembuangan khusus;

f. Tempat untuk menyimpan bahan pengepak harus terpisah dari tempat penanganan;

g. Mempunyai peralatan khusus yang kedap air untuk membuang limbah atau secara langsung dibuang ke laut;

h. Mempunyai tempat penampungan air untuk keperluan penanganan hasil tangkapan;

i. Mempunyai ruang ganti, tempat mencuci tangan, dan toilet dalam jumlah yang cukup. Toilet tidak boleh berhubungan langsung ke tempat penanganan dan penyimpanan hasil tangkapan. Tempat cuci tangan harus dilengkapi dengan keran air mengalir, sabun, dan

Sesuai

$* *)$

$* *)$

Sesuai

$* *)$

Sesuai

Sesuai

Tidak sesuai pengering tangan.

Ruang yang digunakan untuk penanganan atau pembekuan hasil perikanan harus memenuhi persyaratan sebagai berikut :

a. Lantai tidak boleh licin, mudah dibersihkan dan dilengkapi dengan system pembuangan air. Penempatan peralatan tidak boleh

Sesuai menghalangi pembersihan limbah padat dan limbah cair.

b. Dinding dan langit-langit mudah dibersihkan terutama bila terdapat pipa-pipa, aliran listrik atau kabel listrik;

Sesuai

c. Penempatan dan penggunaan mesin hydrolik harus ditata sedemikian rupa untuk mencegah kemungkinan terjadinya kebocoran minyak yang dapat mengkontaminasi produk;

d. Mempunyai ventilasi dan/atau sirkulasi udara yang cukup untuk mencegah terjadinya kondensasi;

e. Mempunyai penerangan yang cukup;

f. Mempunyai peralatan untuk pembersihan dan sanitasi;

g. Mempunyai peralatan untuk mencuci tangan dengan kran yang tidak dioperasikan dengan tangan serta menggunakan pengering sekali pakai.

Peralatan dan perkakas seperti meja pemotong, wadah, ban berjalan, Mesin pembuangan isi perut atau mesin pemfiletan harus tahan karat, mudah dibersihkandan dirawat. 
Hal ini berarti tingkat kecelakaan yang tinggi tidak berarti konsekuensi kecelakaan yang tinggi juga.

Kesesuaian desain dan peralatan kapal Inkamina 163 sebagai kapal penangkap ikan menurut KEPMENKP No.21 (2004) disajikan pada Tabel 6.

Dari ke-17 poin persyaratan pada peraturan pemerintah tersebut, terdapat 8 poin persyaratan yang dapat dijadikan acuan penilaian. Terdapat 7 poin yang sesuai dan 1 poin yang tidak sesuai dengan persyaratan kesesuaian desain dan peralatan pada KEPMENKP No.21/2004.

\section{KESIMPULAN DAN SARAN}

\section{Kesimpulan}

Mengacu pada tujuan dan hasil analisis data, maka dapat disimpulkan bahwa:

1. Kapal Inkamina 163 memiliki kapasitas muat yang sebagian besar sudah dapat memenuhi rencana target operasional kapal.

2. Luas area yang tersisa dari tata letak muatan yang ada, masih mencukupi area kerja $\mathrm{ABK}$ di dek kerja utama (main working deck).

\section{Saran}

Volume ruang mesin yang terlalu besar dari volume estimasi, dapat dikurangi sebagai tambahan ruang ABK. Perubahan desain kapal ikan yang meliputi penambahan, pengurangan, atau pergeseran ruang yang ada dan perubahan tata muatan pada kapal ikan dapat dilakukan. Hal ini dapat dilakukan apabila terlebih dahulu dilakukan perhitungan stabilitas kapal akibat adanya perubahan tersebut.

\section{UCAPAN TERIMA KASIH}

Penelitian ini didukung atas bantuan dana penyelesaian studi dari Bupati Kabupaten Mamasa, Provinsi Sulawesi Barat. Terima kasih disampaikan kepada Bapak Untung Leksono, Pak Ngatno, Pak Agrip Madi, dan teman-teman seangkatan penulis di SD Bobkrigondolayu Yogyakarta.

\section{DAFTAR PUSTAKA}

Akimov, P. (1970). Marine power plant. Troitsky A, penerjemah. Moscow (RUS): Peace Publishers. Terjemahan dari: СУДОВЫЕ СИЛОВЫЕ УСТАНОВКИ. 137.

Antao, P., Almeida, T., Jacinto, C. and Soares, C.D. (2008). Causes of occupational accidents in the fishing sector in Portugal. Safety Science, 46(6), 885-899. doi:10.1016/j.ssci.2007.11.007.

Barras, B. and Derret, B. (2006). Ship stability for master and mates. $6^{\text {th }}$ ed. Oxford(UK): Butterworth-Heinemann.

Brooks, B. (2005). Not drowning, waving!: safety management and occupational culture in an Australian commercial fishing port. Safety science, 43(10), 795-814.

Chauvin, C. and Le Bouar, G. (2007). Occupational injury in the French sea fishing industry: a comparative study between the 1980s and today. Accident Analysis \& Prevention, 39(1), 79-85.

Dickey, D.H. and Ellis, Q. P. (2006). Analysis of fishing vessel casualties. A Review of Lost Fishing Vessels and Crew Fatalities, 19942004. Washington DC: United States Coast Guard, Compliance Analysis Division.

Fyson, J. 1985. Design of small fishing vessels. England (UK): Fishing News Book Ltd.

Gillmer, T.C. and Johnson, B. (1982). Introduction to naval architecture. Maryland (USA): Naval Intitute Press.

Haward, B.M., Lewis, C.H. and Grifin, M.J. 2009. Motions and crew responses on an offshore oil production and storage vessel. Applied Ergonomics. $\quad 40 \quad$ (5):904914.doi:10.1016/j.apergo.2009.01.001.

Husberg, B.J., Lincoln, J.M. and Conway, G.A. (2001). On-deck dangers in the alaskan commercial fishing industry. Proceedings U.S. Safety at Sea, 58(2), 23-24.

ILO. (1999). Safety and health in the fishing industry. Report for discussion at the tripartite meeting on safety and health in the fishing industry, Geneva.

Iskandar, B.H. (2007). Stabilitas Statis Dan dinamis kapal latih stella maris. Buletin PSP, 16(1), 31-49. Fakultas Perikanan, Institut Pertanian Bogor.

Iskandar, B.H. dan Pujiati, S. (1995). Keragaan teknis kapal perikanan di beberapa wilayah 
Indonesia. Laporan penelitian. Bogor (ID): Institut Pertanian Bogor.

Jin, D. and Thunberg, E. (2005). An analysis of fishing vessel accidents in fishing areas off the northeastern United States. Safety Science, 43(8), 523-540.

[KKP] Keputusan Menteri Kelautan dan Perikanan. (2004). Persyaratan kapal penangkap ikan. No. 21. Lampiran 1. Tentang persyaratan desain dan peralatan.

Lee, S.K., Surendran, S. and Lee, G. (2005). Roll performance of small fishing vessel with live fish tank. Ocean engineering, 32(14), 18731885. doi:10.1016/j.oceaneng.2004.11.011.

Lincoln, J.M., Husberg, B.J. and Mode, N.K. (2006). Severe injuries on commercial fishing vessels in Alaska. Third International Fishing Industry Safety and Health Conference. India.

Manullang, S.L. (2008). Kajian stabilitas operasional kapal longline 60 GT. Tesis. Sekolah Pascasarjana. Institut Pertanian Bogor.

Marjoni. (2009). Stabilitas statis dan dinamis kapal purse seine di pelabuhan perikanan pantai lampulo kota Banda Aceh Nangroe Aceh Darussalam. Tesis. Sekolah Pascasarjana. Institut Pertanian Bogor.

Murray, M., and Tilley, N. (2006). Promoting safety awareness in fishing communities through community arts: An action research project. Safety Science, 44(9), 797-808.

Novita, Y. (2011). Pengaruh free surface terhadap stabilitas kapal pengangkut ikan hidup. Buletin PSP, 19(2).

Piniella, F., Soriguer, M.C and Walliser, J. (2008). Analysis of the specific risk in the different artisanal fishing methods in Andalusia, Spain. Safety Science, 46(8), 1184-1195. doi:10.1016/j.ssci.2007.08.006.

Suryanto. (2012). Pengaruh tinggi geladak terhadap keselamatan anak buah kapal pukat cincin yang beroperasi di Selat Bali. Jurnal Kelautan Nasional, 7(2), 109-119.

Suryanto, Hagriyatno, I.T. dan Siwi, W.E.R. (2013). Hubungan variabilitas parameter keamanan dan kenyamanan kerja ABK dan hasil tangkapan ikan pada pukat cincin yang beroperasi di Selat Bali. Jurnal Kelautan Nasional, 8(1), 017-026.

Susanto, A. (2010). Evaluasi desain dan stabilitas kapal penangkap ikan di Palabuhanratu (studi kasus kapal PSP 01). Tesis. Sekolah Pascasarjana. Institut Pertanian Bogor.

Tsai, M.C. and Su, C.C. (2004). Scenario analysis of freight vehicle accident risk in Taiwan. Accident analysis \& prevention, 36(4), 683690. doi:10.1016/j.aap.2003.05.001.

Wahyono, A. (2011). Kapal perikanan (Membangun kapal kayu). Semarang (ID): Balai Besar Pengembangan Penangkapan Ikan.

Wang, J., Pillay, A., Kwon, Y.S., Wall, A.D. and Loughran, C.G. (2005). An analysis of fishing vessel accidents. Journal of Accident Analysis and Prevention, 37(6), 1019-1024. doi:10.1016/j.aap.2005.05.005. 